\title{
EFFECT OF WELDING CURRENT ON MECHANICAL PROPERTIES OF ALUMINUM ALLOYS IN DISSIMILAR JOINT BY GTAW PROCESS
}

\author{
Riswanda $^{1)}$, Sugianto $^{2)}$ \\ ${ }^{1}$ Dosen Politeknik Negeri bandung Jurusan Teknik Mesin Program Studi TPKM \\ ${ }^{2}$ Dosen Politeknik Negeri bandung Jurusan Teknik Mesin Program Studi Aeronaotika \\ Email: ${ }^{1}$ riswanda@ polban.ac.id
}

\begin{abstract}
Welding technique is one of the process connection metal in the manufacturing industry. Aluminum alloys have several advantages including: light, good electrical and corrosion resistant properties. Welding application of dissimilar aluminum alloys with the 5083 and 6061-T6 series such as building structures, bridges, railroad frames, ships and oil platforms. The joining of dissimilar aluminum alloys by welding technique is difficult because the metal has different thermophysis properties. The study aimed of this research to analyze the mechanical properties of variation welding current on joint area GTAW. Visual observation shows that the joint specimen with the low current (100 A) has low penetration in welding groove, whereas at the high current (140 A) undercut occurs on the side of the weld seam, there are spatter and deposits (excessive added material). The hardness test with the current 120 A shows the regular distribution and has the highest tensile test of $201 \mathrm{MPa}$.
\end{abstract}

Keywords : Welding current, dissimilar, GTAW, aluminum alloys.

\section{Pendahuluan}

Aluminium secara umum merupakan meterial atau logam yang banyak digunakan di dunia industri manufaktur. Paduan aluminium merupakan logam yang memiliki keunggulan sehingga banyak digunakan dibidang teknik. Keunggulan paduan aluminium dibandingkan dengan logam lainya antara lain: ringan, mempunyai sifat kunduktivitas listrik yang baik, serta mempunyai sifat tahan terhadap korosi [1]. Paduan aluminium juga banyak digunakan di bidang industri permesinan serta struktur, karena mempunyai kelebihan-kelebihan antara lain: kekuatan tarik relatif tinggi, sifat mekaniknya dapat ditingkatkan dengan pengerjaan dingin atau perlakuan panas, sifat mampu bentuk (formability) yang baik, serta mempunyai sifat mampu las (weldability) yang bervariasi tergantung pada jenis paduannya [2,3].

Proses GTAW (gas tungsten arc welding) atau TIG (tungsten iner gas) salah satu proses pengelasan yang banyak digunakan pada logam aluminium dan paduanya. Gas mulia seperti argon dan helium digunakan pada proses GTAW untuk melindungi dan mencegah oksigen dan hidrogen masuk ke daerah lasan. Pertimbangan menggunakan proses GTAW pada pengelasan aluminium dan paduanya didasarkan pada: penetrasi atau penembusan ke dalam alur atau celah las dapat diatur, sehingga kualitas dan mutu las dapat meningkat baik untuk pelat tipis maupun pelat tebal [4] .

Namun demikian proses GTAW untuk material aluminium dan paduanya masih sering dijumpai cacat las yang mengakibatkan penurunan sifat mekanik seperti kekerasan dan kekuatan tarik di daerah lasan. Faktor-faktor yang dapat mempengaruhi atau menurunkan sifat mekanik hasil pengelasan antara lain: kemampuan operator (welder), serta penentuan parameter diantaranya welding current. Pada penelitian ini aluminium paduan tak sejenis (dissimilar) seri 5083 dan seri 6061-T6 sebagai weld metal dengan bahan tambah (filler) ER- 
5356. Aplikasi sambungan las aluminium paduan tak sejenis (dissimilar) seri 5083 dan 6061T6 antara lain: struktur bangunan, jembatan, rangka kereta api, kapal laut serta oil-platform .

Proses pengelasan logam dissimilar perlu perhatian khusus karena perbedaan metalurgi logam las yang bisa berdampak atau kendala yang beragam. Perbedaan metalurgi logam las akan terjadi pada daerah HAZ (heat affected zone) dan daerah WM (weld metal). Paduan aluminium seri 5083 dan seri 6061 mempunyai sifat yang jauh berbeda antara lain (AA5083) tidak dapat dilakukan perlakuan panas, sedangkan AA6061 dapat diproses perlakuan panas, [6,7,8]. Aluminium paduan seri 6061-T6 kecenderungan terjadinya retak panas (sulit di proses las), sedangkan seri 5083 relatif lebih mudah di proses las [5].

Kualitas hasil las yang memenuhi persyaratan akan ditentukan oleh parameter las diantaranya ketepatan memilih variasi welding current sesuai dengan bahan yang dilas serta kemampuan mesin las yang digunakan. Variasi welding current yang dipilih pada penelitian ini antara lain 100, 120, dan $140 \mathrm{~A}$, diharapkan dengan variasi tersebut akan mendapatkan hasil yang optimal. Kajian dan pengamatan hasil proses GTAW bahan aluminium yang berbeda dalam hal ini daerah lasan akan dilakukan uji kekerasan dan uji kekuatan tarik guna melihat sejauh mana perubahan sifat mekanik antara logam induk (base metal) dan logam las (weld metala). Hasil kajian yang didapat diharapkan dapat diimplementasikan oleh kalangan pengguna dan sekaligus menghasilkan solusi alternatif $[6,7,8]$.

\section{Metodologi Penelitian Flow Chart Diagram}

Gambar 1, menunjukan diagram alir proses penelitian yang dilakukan

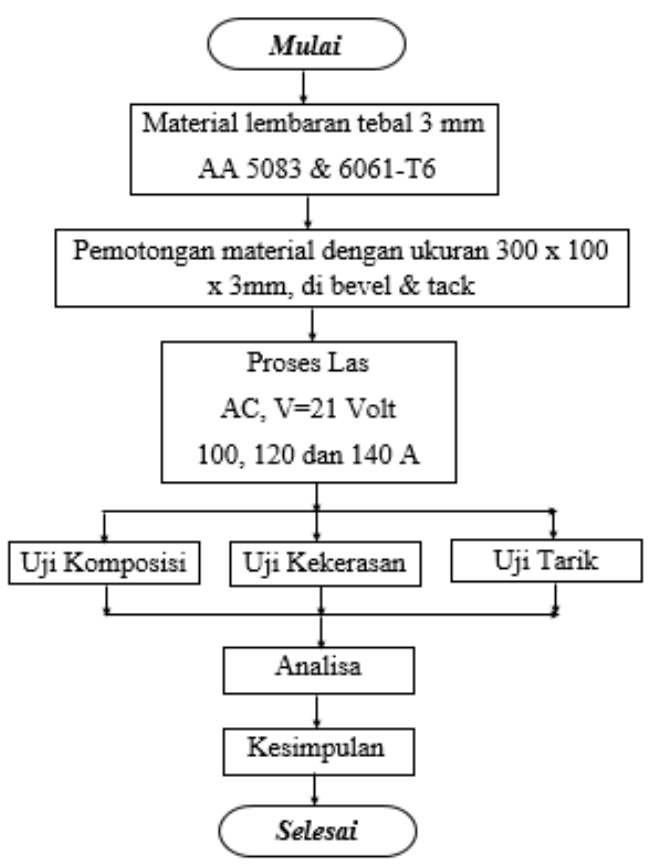

Gambar 1. Diagram alir 


\section{$\underline{\text { Material }}$}

Pemilihan material dalam penelitian ini didasarkan pada aplikasi atau kebutuhan serta keingin tahuan peneliti terhadap hasil proses GTAW pada bahan yang berbeda (dissimilar alumunium allay) yaitu aluminium paduan seri 5083 dan seri 6061-T6 dengan bahan pengisi (filler) ER-5356 diameter 3mm.

\section{Proses Pengelasan}

Data proses GTAW pada penelitian ini antara lain diameter tungsten (tungsten electrode) 2,4 mm, gas pelindung yang di gunakan argon murni sedangkan parameter proses ditunjukan pada Tabel 1.

Tabel 1.Parameter las

\begin{tabular}{|c|c|c|c|}
\hline \multicolumn{4}{|c|}{ Parameter Las } \\
\hline \multicolumn{2}{|c|}{ Jenis Arus AC } & \multirow{2}{*}{$\begin{array}{l}\text { Welding } \\
\text { Speed } \\
(\mathrm{mm} / \mathrm{min})\end{array}$} & \multirow{2}{*}{$\begin{array}{c}\text { Heat } \\
\text { Input } \\
\text { (kJ/mm) }\end{array}$} \\
\hline $\begin{array}{c}\text { Voltage } \\
\text { (V) }\end{array}$ & $\begin{array}{c}\text { Ampere } \\
\text { (A) }\end{array}$ & & \\
\hline \multirow{3}{*}{21} & 100 & 115 & 1,095 \\
\hline & 120 & 125 & 1,209 \\
\hline & 140 & 135 & 1,306 \\
\hline
\end{tabular}

\section{$\underline{\text { Uji Kekerasan }}$}

Uji mikro vickers dilakukan untuk mengetahui sebaran atau distribusi kekerasan baik pada base metal maupun di daerah terpengaruh panas atau HAZ (heat affected zine) dan di daerah las (weld metal). Daerah HAZ pengujian dilakukan dua sisi arah base metal antara lain: sisi arah seri 5083 dan sisi arah seri 6061-T6. Bebean uji mikro vickers yang digunakan adalah 100 gr sedangkan jarak antara titik ke titik 500 un $(0,5 \mathrm{~mm})$. Skematik uji mikro vickers posisi dan jarak uji ditunjukan pada Gambar 2. Nilai kekerasan hasil uji mikro vickers dihitung dengan persamaan 1 .

$$
V H N=\frac{2 \cdot P \cdot \sin (\theta / 2)}{d^{2}}=1,854 \frac{p}{d^{2}}\left(\frac{k g}{m^{2}}\right)
$$

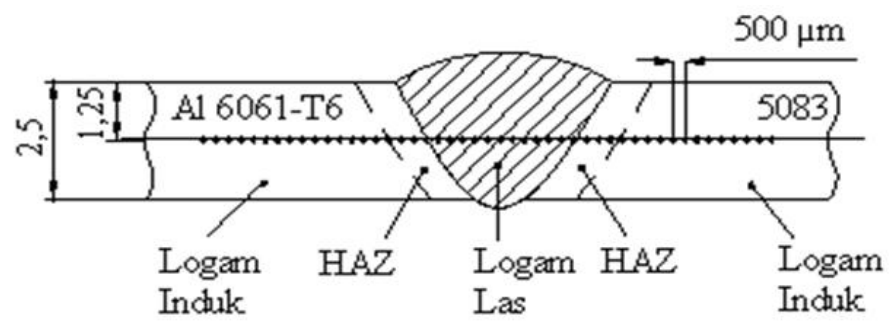

Gambar 2. Posisi dan jarak pengambilan data 


\section{$\underline{\text { Uji Tarik }}$}

Spesimen uji tarik dibuat melintang terhadap arah proses pengelasan dengan standar JIS non - ferrous metal (Z.2201) ditunjukan pada Gambar 3 [9]. Uji tarikdilakukan guna mengetahui seberapa jauh penurunan kekuatan tarik antara logam induk (base metal) jika dibandingkan dengan material setelah di proses las. Hasil uji tarik dalam bentuk data selanjutnya diolah sesuai dengan persamaan baku seperti terlihat pada persamaan 2 dan 3 . Persamaan 2 adalah untuk mendapatkan nilai tegangan tarik, sedangkan persamaan 3 untuk menunjukan regangan atau perpanjangan yang terjadi setelah putus [10].

Tegangan Teknik (Engineering Stress):

$$
\sigma=\frac{F}{A_{0}}
$$

Regangan Teknik Engineering Strain):

$$
\varepsilon=\frac{L-L_{0}}{L_{0}}=\frac{\Delta L}{L_{0}}
$$

dimana :

$\sigma=$ Tegangan tarik $(\mathrm{MPa}), \varepsilon=$ Regangan $(\%), \quad F=$ Beban $(\mathrm{N}), \quad A o=$ Luas penampang mula-mula $\left(\mathrm{mm}^{2}\right), L o=$ Panjang spesimen mula-mula $(\mathrm{mm})$ dan $L=$ Panjang setelah pengujian $(\mathrm{mm})$

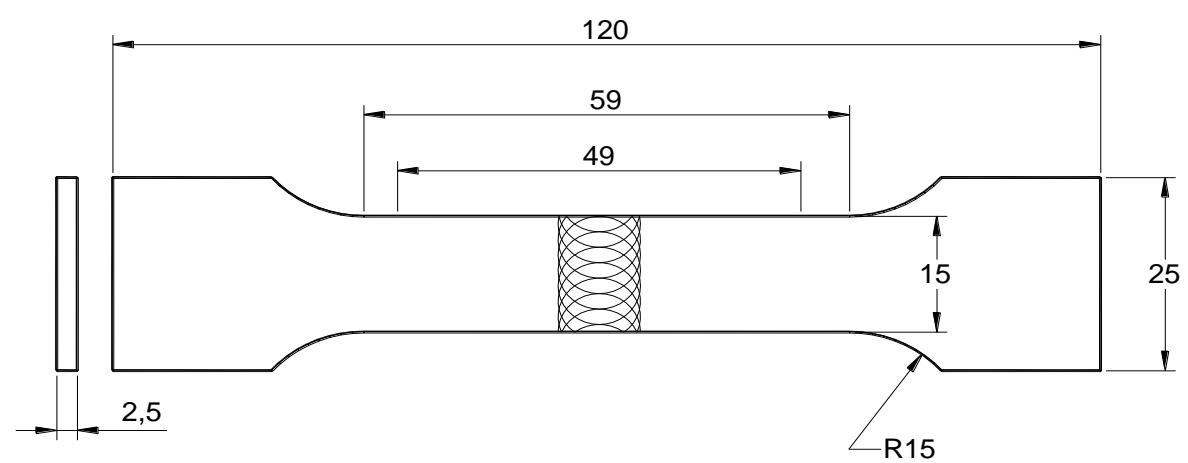

Gambar 3. Spesimen uji tarik satandar JIS Z.2201

\section{Hasil dan Pembahasan}

\section{Karakterisasi Material}

Tabel 2 menunjukan hasil spektometer untuk mengetahui komposisi unsur kimia pada masing-masing benda uji. Uji komposisi pada logan induk dilakukan untuk memastikan bahan yang dipakai sesuai dengan rencana. 
Tabel 2. Hasil uji spektometer

\begin{tabular}{|c|c|c|c|c|c|c|c|c|}
\hline Material & $\mathrm{Si}$ & $\mathrm{Fe}$ & $\mathrm{Cu}$ & $\mathrm{Mn}$ & $\mathrm{Mg}$ & $\mathrm{Zn}$ & $\mathrm{Ti}$ & $\mathrm{Cr}$ \\
\hline $6061-\mathrm{T6}$ & 0,769 & 0,366 & 0,073 & 0,088 & 1,11 & 0,013 & 0,024 & 0,277 \\
\hline 5083 & 1,17 & 0,333 & 0,094 & 0,465 & 4,800 & 0.061 & 0,020 & 0,121 \\
\hline Logam las & 0,45 & 0,304 & 0,05 & 0,285 & 3,55 & 0.021 & 0,025 & 0,131 \\
\hline
\end{tabular}

\section{Analisa visual dan makro struktur}

Gambar 4, menunjukan hasil proses las dan makro struktur. Bagian face adalah tampak muka hasil proses GTAW yang secara kasat mata bisa dianalisa dari bentuk manikmanik las. Makro struktur adalah bentuk spesimen uji yang diambil dari foto makro dari potongan melintang arah proses las (penampang las), untuk melihat hasil tembusan (penetration) dan cacat bagian dalam hasil pengelasan. Bentuk manik-manik las secara visual dibagian face nampak berbedaan dari masing-masing parameter. Pada welding curent $100 \mathrm{~A}$ manik-manik (bentuk permukaan) las cenderung kasar. Hal ini terjadi karena fusi (pembakaran) yang kurang sempurna, sedangkan pada welding curent 140 A menghasilkan manik-manik kurang nampak dan terjadi undercut pada sisi kampuh las. Ini terjadi karena welding curent yang terlalu besar. Secara visual bentuk manik-manik yang paling halus terjadi pada arus 120A. Hasil foto makro pada Gambar 3a tidak terjadi penembusan pada akar las (unpenetration), sedangkan pada Gambar 3c kampuh las melebar dan penambahan bahan tambah yang berlebihan. Hasil pengelasan pada welding curent 120 A menunjukan deposit atau penambahan bahan pengisi pada alur las cukup baik seperti pada Gambar 3b.
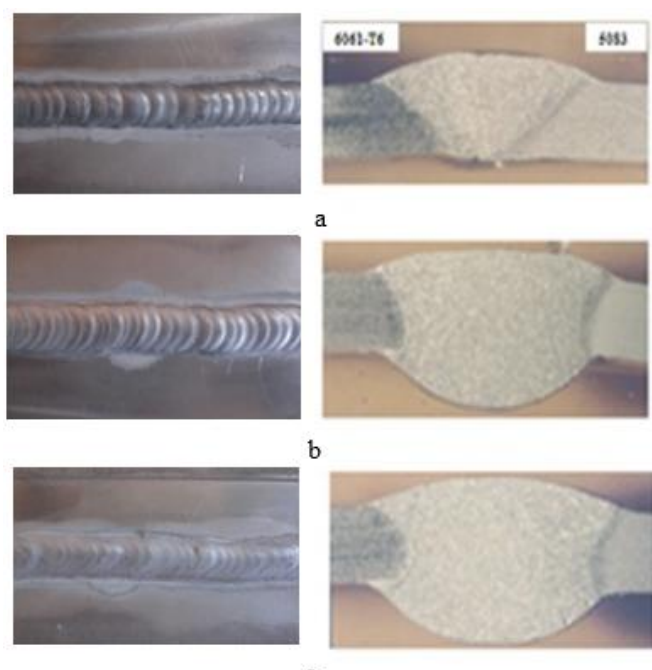

Gambar 4. Hasil proses las dan makro struktur

\section{Analisa hasil uji kekerasan}

Garfik hasil uji kekerasan diambil dari pusat lasan menuju logam induk seperti diperlihatkan pada Gambar 5. Pengambilan data dari dua sisi mengingat seri logam yang berbeda (AA 5083 dan AA 6061-T6) dengan tujuan dapat menganalisa dan membandingkan distribusi kekerasan dari masing-masing area lasan. Perbedaan sebaran atau distribusi terlihat acak di dua sisi daerah HAZ (heat affected zone) (HAZ seri 6061-T6 maupun HAZ seri 5083). Hal tersebut akibat dari sifat metalurgi logam yang berbeda. Daerah HAZ seri 6061T6 arah fusion line (batas weld metal dan HAZ) cendering tinggi terutama di welding current 100 A. Hal tersebut terjadi karena aluminium paduan seri 6061-T6 bersifat (heatreatable) 
dapat diproses perlakuan panas. Distribusi kekerasan daerah lasan terlihat acak disemua parameter, hal tersebut akibat heat input yang terjadi saat proses sehingga di daerah tersebut mengalami peroses pencairan (melting poin) dan diikuti dengan proses pemadatan (solidification). Kekerasan dibagian tengah (daerah las) untuk semua welding current secara umum lebih tinggi dibanding daerah HAZ akan tetapi masih lebih rendah jika dibandingkan dengan logam induknya. Khusus untuk welding curent 120 A dan $140 \mathrm{~A}$, daerah pusat las mengalami pelunakan. Pelunakan juga terjadi pada bagian HAZ untuk kedua bahan.

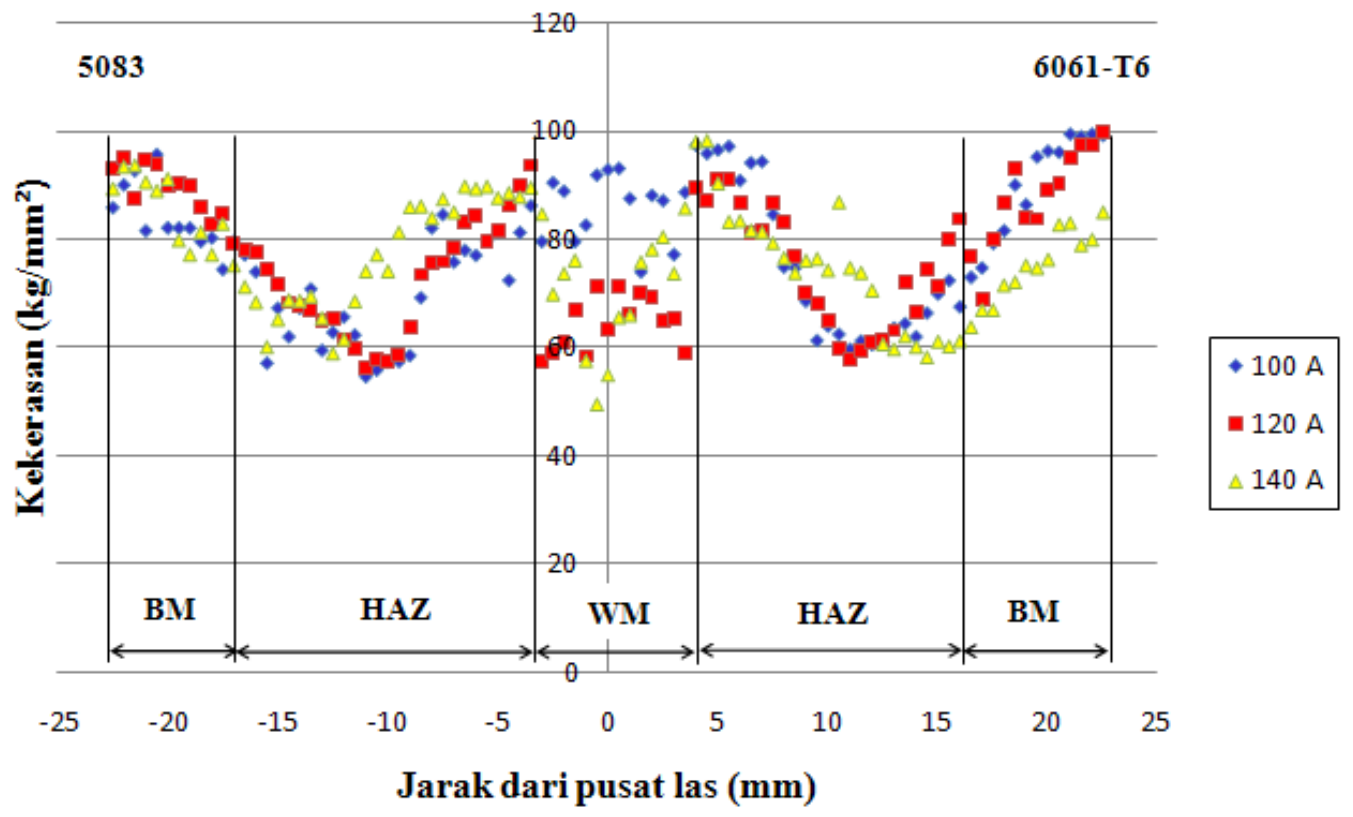

Gambar 5. Hasil uji kekerasan

\section{$\underline{\text { Analisa hasil uji kekuatan tarik }}$}

Pengujian tarik dilakukan dengan 3 spesimen masing-masing welding current termasuk logam induknya (weld metal). Spesimen uji tarik menggunakan standard standar JIS Z2201. Tabel 3 memperlihatkan perbedaan data hasil uji tarik dari masing-masing welding current. Nilai hasil uji kekuatan tarik diambil rata-rata dari masing-masing parameter seperti pada grafik Gambar 6. Nilai kekuatan tarik tertinggi (201 Mpa) terdapat pada welding current $120 \mathrm{~A}$, dan nilai kekuatan tarik terendah (189 Mpa) terdapat pada parameter (welding current) 100 A. Gambar 7, menunjukan posisi patahan hasil uji tarik. Spesimen dengan welding curent $100 \mathrm{~A}$ terjadi patah pada logam las (weld metal) bentuk patahan getas dan terdapat porositi. Hal ini terjadi karena kurangnya fusi serta penetrasi logam pengisi kedalam alur las tidak sempurna. Spesimen uji pada welding curent 120 A patahan terjadi di daerah HAZ Al 5083, sedangkan untuk spesimen uji dengan welding curent 140 A patah pada derah HAZ Al 6061-T6. Hasil pengujian tarik ini menunjukan konsistensi terhadap hasil uji kekerasan. 
Tabel 3. Hasil uji tarik

\begin{tabular}{|c|c|c|c|c|c|c|c|c|c|c|c|c|c|c|}
\hline \multirow{3}{*}{ No } & \multirow{3}{*}{$\begin{array}{c}\text { Hasi } \\
\text { Pengyian }\end{array}$} & \multirow{3}{*}{ Spesimen } & \multicolumn{6}{|c|}{ Dimensi } & \multicolumn{4}{|c|}{ Hasil Perhitungan } & \multicolumn{2}{|c|}{ Rata-rata } \\
\hline & & & Lo & $\mathrm{L} 1$ & Wo & $t$ & $\Delta \mathrm{L}$ & Ao & $F_{m a x}$ & $\varepsilon$ & $\sigma_{\operatorname{ma}}$ & $\sigma_{y \max }$ & $\sigma_{\mathrm{ma}}$ & $\sigma_{y=n}$ \\
\hline & & & $(\mathrm{mm})$ & $(\mathrm{mm})$ & $(\mathrm{mm})$ & $(\mathrm{mm})$ & $(\mathrm{mm})$ & $\left(\mathrm{mm}^{2}\right)$ & (N) & (6) & $(\mathrm{Mpg})$ & (Mps) & (Mps) & (Mpa) \\
\hline \multicolumn{15}{|c|}{ LOGAM NDUK (BASE METAL) 6061-I6 } \\
\hline 1 & 31,96 & 1 & 49 & 00,2 & 15 & 25 & 11,2 & 375 & $12517 \phi$ & 2286 & 3338 & 278,2 & \multirow{3}{*}{3338} & \multirow{3}{*}{$2 \pi, 0$} \\
\hline 2 & $31,9 \%$ & 2 & 49 & 田2 & 15 & 25 & 10.2 & 375 & $12317 \%$ & 2002 & 3338 & 276,4 & & \\
\hline 3 & $31,9 \times$ & 3 & 49 & 588 & 15 & 25 & 98 & 375 & 125178 & 2000 & 3338 & 276,4 & & \\
\hline \multicolumn{15}{|c|}{ LOGAM NDUUK (BASE METAL) 5083} \\
\hline 1 & $30,1 \%$ & 1 & 49 & 575 & 15 & 25 & 85 & 375 & 11811,2 & 1735 & $315 p$ & 265,8 & \multirow{3}{*}{3185} & \multirow{3}{*}{207,2} \\
\hline 2 & $39,0 \mathrm{x}$ & 2 & 49 & 573 & 15 & 25 & 83 & 375 & $12007 / 4$ & 1694 & 32002 & 271,5 & & \\
\hline 3 & $390 \pi$ & 3 & 49 & 571 & 15 & 25 & 81 & 375 & $12007 / 4$ & 1653 & 3202 & 264,3 & & \\
\hline \multicolumn{15}{|c|}{100 Amper } \\
\hline \begin{tabular}{|l|}
1 \\
\end{tabular} & $15,0 \%$ & 1 & 49 & 495 & 15 & 24 & 05 & 36 & 5tas, 0 & 19 & 1035 & 125,4 & \multirow{3}{*}{$18 \$ 9$} & \multirow{3}{*}{1259} \\
\hline \begin{tabular}{|l|}
2 \\
\end{tabular} & $18,8 \%$ & 2 & 49 & 53.2 & 15 & 24 & 42 & 36 & 737,1 & 857 & 2049 & 125,7 & & \\
\hline 3 & 18,25 & 3 & 49 & 528 & 15 & 24 & 38 & 30 & 741,7 & 7,70 & 1984 & 126,7 & & \\
\hline \multicolumn{15}{|c|}{120 Amper } \\
\hline \begin{tabular}{|l|}
1 \\
\end{tabular} & $17.8 \%$ & 1 & 49 & 586 & 15 & 24 & 4,6 & 36 & at,7 & 939 & 1940 & 123.5 & \multirow{3}{*}{2013} & \multirow{3}{*}{130,5} \\
\hline 2 & $18,5 \%$ & 2 & 49 & 538 & 15 & 24 & 48 & 36 & 72984 & $9 \times 0$ & 2017 & 127.4 & & \\
\hline 3 & $19,1 \%$ & 3 & 49 & 543 & 15 & 24 & 53 & 36 & 7494,8 & 1082 & 2002 & 140.5 & & \\
\hline \multicolumn{15}{|c|}{140 Amper } \\
\hline 1 & $17,7 \%$ & 1 & 49 & 표 & 15 & 24 & 43 & 36 & $\cos 5$ & 878 & 1929 & 125,1 & \multirow{3}{*}{199,5} & \multirow{3}{*}{ 1301 } \\
\hline 2 & $18,0 \%$ & 2 & 49 & 53,7 & 15 & 24 & 4,7 & 36 & 73036 & 99 & 2028 & 128,1 & & \\
\hline \begin{tabular}{|l|} 
\\
\end{tabular} & $18,0 \%$ & 3 & 49 & \$18 & 15 & 24 & 4,6 & 36 & 7284,6 & 939 & 2027 & 137,0 & & \\
\hline
\end{tabular}

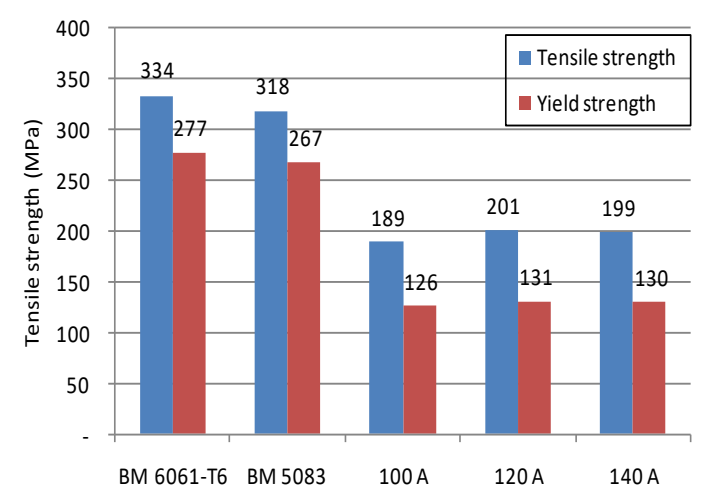

Gambar 6. Grafik kekuatan tarik
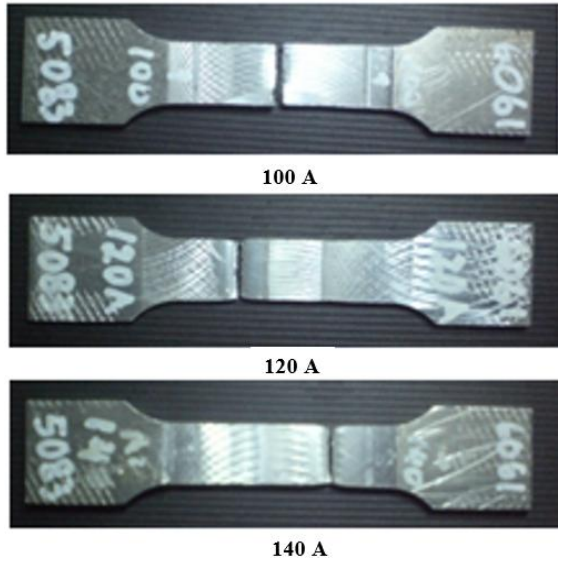

Gambar 7. Posisi patahan hasil uji tarik

\section{Kesimpulan}

Hasil yang diperoleh dari penelitian tersebut antara lain:

1. Pengamatan visual dan foto makro menunjukan bahwa hasil pengelasan spesimen dengan welding current kecil (100A) penembusan (penetration) logam pengisi kedalam alur las kurang, sedangkan pada welding current besar (140A) terjadinya percikan busur (spatter) dan pelelehan yang berlebihan serta terjadi undercut.

2. Welding curent $100 \mathrm{~A}$, pada logam las terjadi peningkatan kekerasan yang relatif tinggi tetapi kekuatan tariknya rendah. Hal ini dikarenakan kurangnya fusi, penetrasi pada alur las tidak sempurna serta indikasi adanya porositi sehingga patah getas terjadi pada logam las.

3. Pada welding curent $120 \mathrm{~A}$, terjadi pelunakan pada daerah HAZ logam induk Al 5083, sedangkan pada arus 140 A pelunakan terjadi di bagian HAZ Al 6061-T6. Hal 
tersebut karena sifat metalurgi kedua aluminium paduan tersebut berbeda. Hasil uji kekuatan tarik juga menunjukan konsistensi terhadap uji kekerasan yaitu masingmasing patahan terjadi pada daerah yang lunak.

\section{Ucapan Terimakasih}

Penelitian ini di biayai oleh Politeknik Negeri Bandung dengan Surat Perjanjian Pelaksanaan Penelitian Terapan Nomor 351.6/PL1.R7/LT/2019. Oleh sebab itu diucapkan terimakasih ditujukan kepada pihak-pihak yang membantu selesainya penelitian ini yaitu:

- Jajaran Manajemen Politeknik Negeri Bandung

- Unit Penelitian dan Pengabdian kepada Masyarakat Politeknik Negeri Bandung

- Para Reviewer Penelitian Internal Politeknik Negeri Bandung

- Para rekan sejawat di Jurusan Teknik Mesin-Politeknik Negeri Bandung

\section{Daftar Pustaka}

[1] Vijay, S., Rajanarayanan, S., \& Ganeshan, G. N. (2019). Analysis on mechanical properties of gas tungsten arc welded dissimilar aluminium alloy (Al2024 \& Al6063). Materials Today: Proceedings.

[2] Gejendhiran S dkk.(2014).A Study of Welding Parameters on Mechanicak Properties of Gas Metal Arc Welding and Gas Tungsten Arc Welding:A Review. International Journal of Advanced Engineering Research and Studies, E-ISSN2249-8974

[3] R Ahmad. (2018).The Effect of Aging Time on Mechanical and Microstructure Properties of Aa6061 Joint Welded by Gas Tungsten Arc Welding. Joj Material Sci 4 (5) JOJMS ID 555646

[4] Arun, M., \& Ramachandran, K. (2015). Effect of welding process on mechanical and metallurgical properties of AA6061 aluminium alloy lap joint. International Journal of Mechanical Engineering and Research, 5, 162-178.

[5] Balasubramanian, K., Balaji, N., \& Rajesh, E. K. Mechanical Properties of Aluminum 6063 Alloy Joined by Tungsten Inert Gas Welding and Friction Stir Welding Methods.

[6] Vijay Mohan Shetty, dkk. (2018). Optimizatio and Evaluation of Ageing Parameter on Mechanical Properties of AA 6061 and AA 5154 Welding Joint Using Taguchi Method. International Journal of Egineering Sciences \& Research Technology, ICTM Value: 3.00 CODEN: IJESS7

[7] Patil, P. C., \& Shelke, R. D. (2015). Review on welding parameter effects on TIG welding of aluminium alloy. International Journal of Engineering Research and General Science, 3(3), 1479-1486.

[8] Riswanda, R., \& Ilman, M. N. (2012, July). Studi Komparasi Sambungan Las Dissimilar AA5083-AA6061-T6 Antara TIG dan FSW. In Prosiding Industrial Research Workshop and National Seminar (Vol. 3, pp. 75-79).

[9] JIS. (1973). Non Ferrous Metal.Japanese International Standar.

[10] Kou, S. (2003). Welding Metallurgy. 2 ed., John Wiley \& Sons, Inc., Canada. 